\title{
Spatial Modelling of Lead (Pb) Concentration for the Soil in Sokoto Rima Basin, Using Co-Kriging
}

\author{
Umar Usman ${ }^{1, ~ *, ~ M u d d a s s i r u ~ A b u b a k a r ² ~}$ \\ ${ }^{1}$ Department of Mathematics, Usmanu Danfodiyo University, Sokoto, Nigeria \\ ${ }^{2}$ Department of Mathematics, Federal University Birnin Kebbi, Kebbi, Nigeria
}

Email address:

uusman07@gmail.com (U. Usman)

${ }^{*}$ Corresponding author

\section{To cite this article:}

Umar Usman, Muddassiru Abubakar. Spatial Modelling of Lead ( $\mathrm{Pb})$ Concentration for the Soil in Sokoto Rima Basin, Using Co-Kriging. International Journal of Statistical Distributions and Applications. Vol. 6, No. 2, 2020, pp. 36-41. doi: 10.11648/j.ijsd.20200602.12

Received: March 17, 2020; Accepted: April 7, 2020; Published: August 25, 2020

\begin{abstract}
This study used Geostatistics techniques to find the variability in the concentration of lead $(\mathrm{Pb})$ in Sokoto Rima Basin Region. The concentrations Lead $(\mathrm{Pb})$ were measured and analyzed in one hundred and three (103) different sample points in Sokoto Rima Basin region of Nigeria. The region is characterized as one of the center for agricultural activities in Nigeria. The soil samples were collected from agricultural, industrial and residential areas. The concentrations of heavy Lead $(\mathrm{Pb})$ were measured using Atomic Absorption Spectrometer. The technique of Co-Kriging was used to develop empirical semivariogram model to predict the concentrations of Lead $(\mathrm{Pb})$ in the soil. The result shows that concentrations of Lead $(\mathrm{Pb})$ have exceeded the standard level in the study area. The study revealed that there are extreme concentrations of heavy metals in the central region of the study area.
\end{abstract}

Keywords: Heavy Metal, Concentrations, Variogram, Co-Kriging

\section{Introduction}

Soil is a mixture of organic matter, minerals, gases, liquids and other organisms that together support life. It is the product of several factors; it is classified into different types. It is critical to many ecosystem functions, and soil degradation and pollution have gained great deal of attention worldwide [1] Contaminated soil soils can pose serious threat to human health through the variety of different pathways including diet, inhalation and dermal contact [1]. Soil pollution has become a serious problem in Nigeria as a result of rapid industrial and agricultural activities that occur in the last several decades. Several factors that can contaminated soil are the heavy metals that are present in the soil. The metals are classified as "heavy metals" if they have a specific gravity of more than $5 \mathrm{~g} / \mathrm{cm}^{3}$ [2]. Heavy metals gets accumulated in soils and plants causing negative influence on photosynthesis, gaseous exchange and nutrient absorption of plants resulting in the reduction of plant growth, dry matter accumulation and yield [3]. Heavy metals contamination of soil result mainly due to mining, smelting and agriculture as well as natural activities [2]. There has been a rapid increase in the agricultural activities in Sokoto Rima basin, which in one way or the other has caused the soil to be toxic, which in turn can cause the soil contamination. Heavy metals in the soil continue to contaminate as a result of such agricultural activities that increases the concentration of these heavy metals. Apart from agricultural activities, residential and industrial wastewater are discharged randomly on the soil, into canals, rivers, along roadside or in the vicinity of industries operation without treatment. They pollute the productive soil, natural water system as well as ground water. These residential and industrials wastewater contain medium amount of heavy metals such as chromium $(\mathrm{Cr})$, lead $(\mathrm{Pb})$ and iron (Fe) [2]. Emission of gases from vehicles, residential and industrial activities could cause higher concentration of heavy metals in the soil; these gases when emitted would increase the concentrations of those metals and to soil contamination [4]. Metals such as cadmium, chromium, copper, lead and zinc contaminate soil as a result of cement production [5]. These heavy metals are deposited into soil at various distance [6] depending on wind velocity and particles size [7] through the cement dust and stack 
fumes. Majority of heavy metals in the cement dust originated from raw material $[8,9]$. Reported that typical cement raw material contains $25 \mathrm{mg} / \mathrm{kg}$ of chromium $(\mathrm{Cr}), 21$ $\mathrm{mg} / \mathrm{kg}$ of copper $(\mathrm{Cu}), 20 \mathrm{mg} / \mathrm{kg}$ of lead $(\mathrm{Pb})$ and about $50 \%$ of the total cadmium $(\mathrm{Cd})$, copper $(\mathrm{Cu})$ and zinc $(\mathrm{Zn})$ load in the cement are introduce through raw materials. Majority of emitted heavy metals are known to be toxic to humans and plants, even at low concentrations [10] with very large set of health consequences. To adopt any type of remedial measures, it is necessary to determine heavy metals' load in the contaminated soil. Against these background information, it is necessary to analyze heavy metals concentration in and around this region in order to find proper remedy to the problem. Concentration of heavy metals pollution generally a non-stationary variable [2]. Due to the different type of heavy metals in the soil and high spatial variation in their concentration, more accuracy is needed in the application of method to analyze their concentrations. In view of capability of these methods to be used in conjunction with GIS and the expansion of the application of GIS, the importance of selecting the Kriging technique as suitable method of interpolation arises.

Kriging is named after the South African engineer, D. G. Krige, who first developed the method. The technique was first published by Krige [11] later the mathematical equations and concepts related to Kriging were formulized by Matheron [12] and basically established the whole field of linear geostatistics [13]. Kriging is a statistical method based on the theory of regionalized variables and variogram model. It is considered to be the best linear unbiased predictor (BLUP) that satisfies a certain optimality criterion. It is a spatial prediction method which predicts at any point based on the average values at sampled points the weights given to each sample points are optimal. Kriging is a technique of making optimal, unbiased estimates of regionalized variable at un-sampled locations using the structural properties of the semivariogram and initial set of data values [14]. Kriging takes into consideration about the spatial structures of the parameter and hence it is having definite advantage over the other methods like arithmetic mean method, nearest neighbor method, distance weighted method and polynomial interpolation [2]. In addition, Kriging provide the estimation variance at every estimated point, which is an indicator of accuracy of the estimated value and was considered as the major advantage of Kriging over some interpolation techniques. Spatial variation in soil has been recognized for many years [15]. Geostatistics has been applied in soil science for more than 20 years, has provided modern techniques to quantify the spatial soil parameters, and performed spatial interpolation [16. 17]. The spatial distribution of Soil is generally consistent with elevation and precipitation [18. 16] were the first to use kriging and its practical application, in soil survey, later many other pedologists and environmental scientists have followed it in their literature. Many authors [19. 20] have written excellent accounts of geostatistics and its underlying concepts for soil scientists. Geostatistical methods which consider environmental correlation in prediction include Co-kriging, kriging within strata, kriging with external drift, and regression kriging [21, 22].

To quantify the distribution of spatial patterns and changes in heavy metals concentrations, geostatistics has been applied. [23] studied the spatial distribution of heavy metals in the middle Nile Delta of Egypt. They found that all heavy metals in the study area exceeded crustal mean value specified by [24]. The concentration of $\mathrm{Ni}$ and $\mathrm{Cr}$ exceeded recommended values in the soil profile horizon, while " $\mathrm{Cu}$ " had a variable distribution and " $\mathrm{Zn}$ " concentration are under recommended concentration limit in the most soil sample. They recommended that heavy metal contamination should be investigated within the entire soil profile and not just top-soils, because of the high mobility of these metals, which could affect soil and crop quality and Cause underground water pollution. [8] studied contamination and spatial distribution of heavy metals in top-soil surrounding the cement factory in Sagamu, southwest of Nigeria. The study revealed that there was extreme concentration of $\mathrm{Cd}$ in the region and severe contamination by $\mathrm{Pb}$ and $\mathrm{Cu}$. They concluded that the enrichment of the soil by $\mathrm{Cd}$ was due to cement production activities. [25] studied spatial prediction of heavy metals pollution for soils in Coinbotore, India based on ANN and Kriging model. They found that the residential areas are contaminated with $\mathrm{Cr}$ and moderately with $\mathrm{Pb}$. They concluded that the highest concentration of heavy metals in those industrial polluted areas are not only problem with respect to plant nutrient and food chain contamination but also caused a direct health hazard to human and animals, which needed effective and affordable technological solutions. [2] studied spatial prediction of heavy metals pollution for soils in Coinbatore, India based on Universal Kriging. They found that the reason for maximum $\mathrm{Pb}$ at Ukkadam Lake was due to discharging of sewage water into the lake. $\mathrm{Cr}$ concentration ranged between $0-3.6 \mathrm{ppm}$. Maximum concentration was in Ganapathy because of the concentration of foundry industry. Fe ranged between $0-$ 5.29. Maximum at Sidco Industrial Estate and Singanallur because of the concentration of electroplating industry. They observed that maximum heavy metal pollution near the industrial, traffic junction where traffic jams and the legendary 'go-slow' of automobiles was the order of the day and in localities of large population concentration and relatively small areas under poor conditions of sanitation. They used Kriging model to predict the heavy metal at the unknown point. From the model of heavy metals, they conclude that the residential areas are uncontaminated with $\mathrm{Cr}$ and moderately contaminated with $\mathrm{Pb}$ and Fe. [4] studied spatial distribution of heavy metals and environmental quality of soil in the northern plateau of Spain. They found that among several metals components in the soil, the coefficient of variation of $\mathrm{Pb}$ and $\mathrm{Hg}$ were 0.80 and 0.76 respectively were the highest, implying that these two metals had greater variability throughout the area studied compared to other metals also present in the soil. 
They concluded that agricultural activities could continue, but there should be some improvement measures to protect the security of agriculture. [26] studied how climate change can affect the vegetation in the northern part of Nigeria. They found that it is possible to apply Co-Kriging to determine how climatic variation can change the vegetation in the northern part of Nigeria. [27] identified that geostatistical techniques are methods appropriate to assed the vegetation productivity in the northern part of Nigeria. They used modelling techniques to determine how changes in climate could affect vegetation productivity in the northern part of Nigeria. [28] studied spatial variability of heavy metals in the soil of Ahwaz using the geostatistical method; they found that Lead $(\mathrm{Pb})$ contamination is about 33 percent of the study area is more than the standard level, they conclude that Lead concentration is control by anthropogenic activities connected with traffic and industries. [29] used Co-Kriging to study spatial distribution and mobility assessment of carcinogenic heavy metals in the soil profile, they reveals that $\mathrm{Pb}$ and $\mathrm{Cr}$ have spatial variability regarding subsoil horizons. [1] studied spatial modelling of $\mathrm{Cr}, \mathrm{Pb}, \mathrm{Cd}$, As and $\mathrm{Ni}$ in soil based on portable X-ray fluorescence and Geostatistics in east China. The study reveals that $\mathrm{Cd}$ is the primary pollutant element in Fuyang, followed by $\mathrm{As}$ and $\mathrm{Pb}$. They also revealed that heavy metals pollutions were mainly as a result of mining, industrial and traffic activities, and irrigation with polluted water. They concluded that PXRF and Co-Kriging as the efficient and reliable method for soil heavy metals assessment and mapping. The aim of this research is to investigate Lead $(\mathrm{Pb})$ Concentration for the Soil in Sokoto Rima Basin, Using Co-Kriging.

\section{The Study Area}

The study area comprises of one hundred and three (103) sample points located in Sokoto Rima basin of northern Nigeria. The study area falls between latitude $10.9^{\circ}$ to $14^{\circ} \mathrm{N}$ and longitude $3.5^{\circ}$ to $7.1^{\circ} \mathrm{E}$. The area is characterized as one of the centers of agriculture in the country. The map of the study is shown in figurel below.

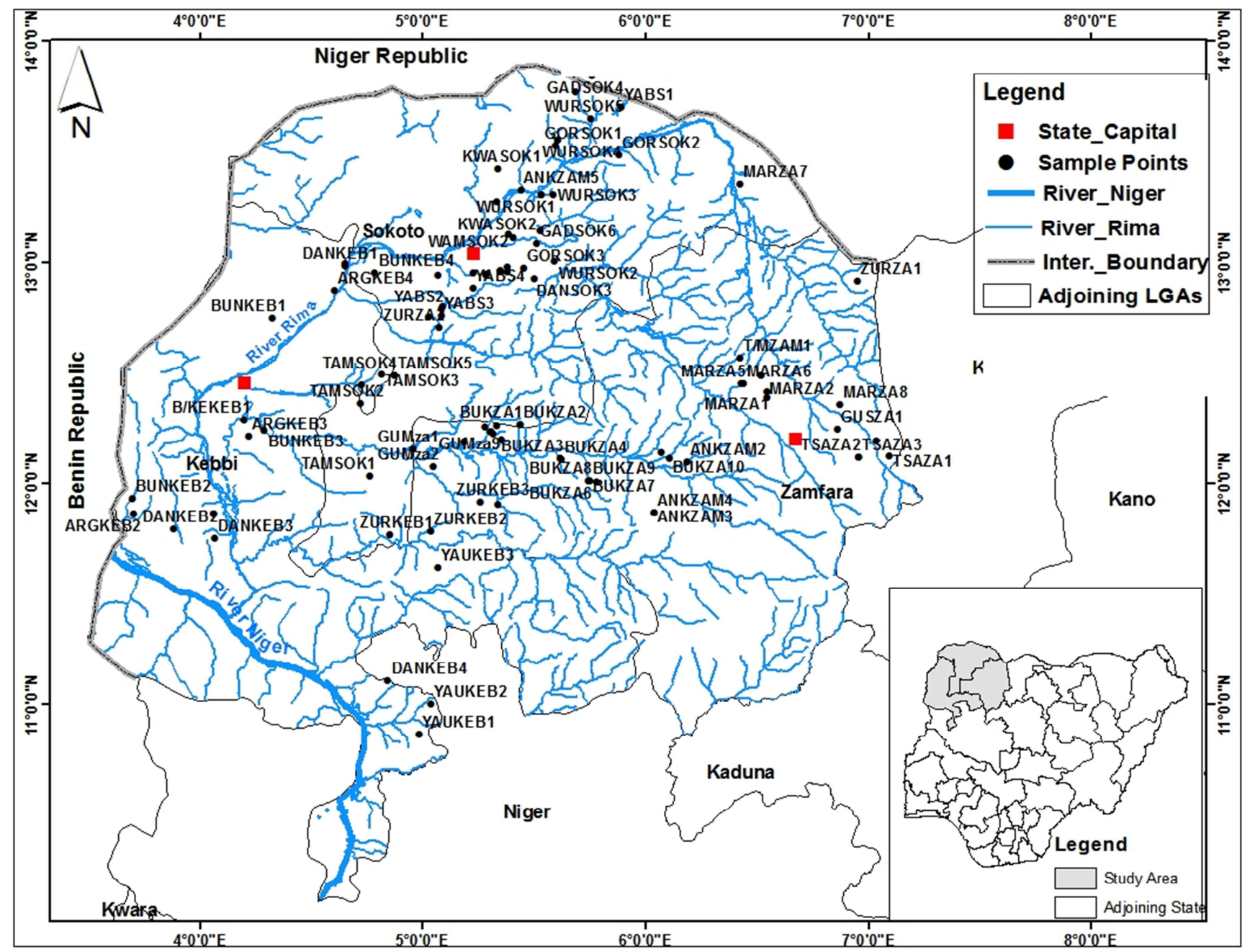

Figure 1. The study area showing one hundred and three (103) sample points in Sokoto Rima basin. 


\subsection{Data and Methods}

In this research, a data recorded in one hundred and three (103) sample points located in Sokoto Rima Basin of northern Nigeria were analyzed. The data set contains Lead $(\mathrm{Pb})$ as input variable for the analysis. Other datasets utilized in this study are Elevation and Geo-coordinates location.

\subsection{Co-Kriging Modelling}

In pure geostatistical approach, predictions are commonly made by calculating some weighted average of the observations [13]:

$$
\hat{z}\left(s_{0}\right)=\sum_{i=1}^{n} \lambda_{i} \cdot z\left(s_{i}\right)
$$

Where $\hat{z}\left(s_{0}\right)$ is the predicted value of the target variable at an unvisited location $s_{0}$ gives its map coordinates, the sample data $\left(s_{1}\right), z\left(s_{2}\right), \ldots, z\left(s_{n}\right)$ and their coordinates. The weights $\lambda_{i}$ are chosen such that the prediction error variance is maximized, yielding weights that depend on the spatial autocorrelation structure of variable. This interpolation procedure is popularly known as Ordinary Kriging (OK), for $i=1,2, \ldots n$

The first step in Kriging is the calculation of the experimental semivariogram using the following equation.

$$
\gamma^{*}(h)=\frac{1}{2 N(h)} \sum_{i=1}^{N(h)}\left(z\left(X_{i}\right)-z\left(X_{i+h}\right)\right)^{2}
$$

Where $\gamma^{*}(h)$ is estimated value of the semi variance for lag $h, N(h)$ is the number of experimental pairs separated by vector $h, z\left(X_{i}\right)$ and $z\left(X_{i+h}\right)$ are the value of the variable $z$ at $X_{i}$ and $X_{i+h}$ respectively, $X_{i}$ and $X_{i+h}$ is the position in two dimension.

An extension of ordinary kriging is Co-Kriging approach in case of two or more spatial or spatiotemporal variables. In Co-Kriging, the explanatory variables are spatial, temporal or spatiotemporal with expected values and variogram as compared to ordinary Kriging in which explanatory variable are fixed [30].

A Co-Kriging estimate is a linear combination of both primary and secondary data value as shown by [31] in given equation:

$$
\hat{z}\left(s_{0}\right)=\sum_{i=1}^{n} \lambda_{i} X_{i}+\sum_{j=1}^{m} \tau_{j} Y_{j}
$$

Where $\hat{Z}\left(s_{0}\right)$ is the estimated of $\mathrm{z}$ at location 0 ; $X_{1}, X_{2}, \ldots, X_{n}$ are the primary data at $\mathrm{n}$ nearby locations; $Y_{1}, Y_{2}, \ldots, Y_{m}$ are secondary data at $\mathrm{m}$ nearby locations; $\lambda_{1}, \lambda_{2}, \ldots, \lambda_{n}$ and $\tau_{1}, \tau_{2}, \ldots, \tau_{m}$ are Co-Kriging weights to be estimated.

The development of Co-Kriging system is identical to the development of ordinary Kriging system.

The definition of estimation error is stated as:

$$
R=\hat{z}\left(s_{0}\right)-z\left(s_{0}\right)=\sum_{i=1}^{n} \lambda_{i} X_{i}+\sum_{j=1}^{m} \tau_{j} Y_{j}-z\left(s_{0}\right)
$$

Where $X_{1}, X_{2}, \ldots, X_{n}$ are random variables representing $\mathrm{X}$ at the $\mathrm{n}$ locations and $Y_{1}, Y_{2}, \ldots, Y_{m}$ are random variable representing $\mathrm{Y}$ at the $\mathrm{m}$ locations.
An expression for the variance of the estimations error in terms of Co-Kriging weight and the covariance between the random variables are:

$$
\begin{array}{r}
\operatorname{Var}(R)=\sum_{i=1}^{n} \sum_{j=1}^{m} \lambda_{i} \lambda_{j} \operatorname{cov}\left\{X_{i} X_{j}\right\}+\sum_{i=1}^{n} \sum_{j=1}^{m} \tau_{i} \tau_{j} \operatorname{cov}\left\{Y_{i} Y_{j}\right\} \\
+2 \sum_{i=1}^{n} \sum_{j=1}^{m} \lambda_{i} \tau_{j} \operatorname{cov}\left\{X_{i} Y_{j}\right\}- \\
2 \sum_{i=1}^{n} \lambda_{i} \operatorname{cov}\left\{X_{i} X_{0}\right\}-2 \sum_{j=1}^{m} \tau_{i} \operatorname{cov}\left\{Y_{j} Y_{0}\right\}+\operatorname{cov}\left\{X_{0} X_{0}\right\}(5)
\end{array}
$$

Where $\operatorname{cov}\left(X_{i} X_{j}\right)$ is auto-covariance between $X_{i}$ and $X_{j}$, $\operatorname{cov}\left(Y_{i} Y_{j}\right)$ is auto-covariance between $Y_{i}$ and $Y_{j}$ and $\operatorname{cov}\left(X_{i} Y_{j}\right)$ is the cross-covariance between $X_{i}$ and $Y_{j}$.

The set of Co-Kriging weights thus, must satisfy two conditions. First, the weight must to be such that the estimate in equation (3) is unbiased. Second, the weight must be such that the error variances given in equation (5) are the smallest possible. One way of guaranteeing unbiasedness is to ensure that the weights in the first term sum to 1 while in the second term sum to $0[32,33]$

$$
\sum_{i=1}^{n} \lambda_{i}=1 \text { and } \sum_{j=1}^{m} \tau_{j}=0
$$

The Lagrange multiplier method may be used to minimize the error variance with two constrains. To implement the method, we simply equate each nonbiased condition to 0 , multiply by a Lagrange multiplier and add to the result to each equation (5). This give the following expression.

$$
\operatorname{Var}(R)=W^{t} C_{z} W+2 \mu_{1}\left(\sum_{i=1}^{n} \lambda_{i}-1\right)+2 \mu_{2}\left(\sum_{j=1}^{m} \tau_{j}\right)(7)
$$

Where $\mu_{1}$ and $\mu_{2}$ are Lagrange multiplier. The minimized error variance can be calculated using (5) or it can be simplified by making substitutions using the Lagrange multipliers. The simplified version is

$$
\begin{aligned}
\operatorname{Var}(R)= & \operatorname{cov}\left\{X_{0} Y_{0}\right\}+\mu_{1}-\sum_{i=1}^{n} \lambda_{i} \operatorname{cov}\left\{X_{i} X_{0}\right\}- \\
& \sum_{j=1}^{m} \tau_{i} \operatorname{cov}\left\{Y_{j} Y_{0}\right\}
\end{aligned}
$$

It exploits more fully auxiliary information by directly incorporating the value of auxiliary variable and measuring the degree of spatial association with primary variable through the cross-semivariogram. The technique of CoKriging improves the estimation and reduces the variance of the estimation error, but at the same time is much more demanding than Ordinary Kriging. The calculation of the cross-semivariogram and the fitting of a theoretical model become very difficult, particularly when the two variables are not strongly correlated [34].

\section{Result and Discussion}

The experimental variogram of Lead $(\mathrm{Pb})$ is shown in Figure 2. The variogram model indicated that there is a spatial autocorrelation in the model. However, the prediction variability in the concentration of Lead $(\mathrm{Pb})$ indicated that the concentration of Lead $(\mathrm{Pb})$ is increasing from north to southern part of the study area around Kware, Gada, Dange, 
Wurno and Bukuyum. The Kriging elevation map for the Lead $(\mathrm{Pb})$ indicated that the highest variability in the concentration of Lead $(\mathrm{Pb})$ is in the middle part of the study area. The Co-Kriging prediction and Co-Kriging standard error for the Lead is shown in figures 3 and 4.

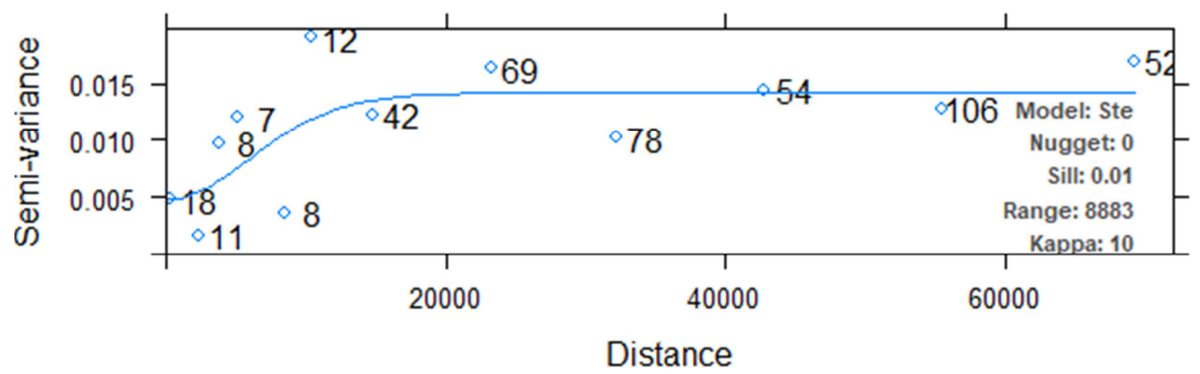

Figure 2. The experimental and fitted variogram of Lead $(P b)$.

\section{Kriging prediction}

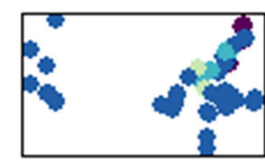

$[6.438,6.522]$

$(6.522,6.606]$

$(6.606,6.69]$

- $\quad(6.69,6.775]$

- $\quad(6.775,6.859]$

- $\quad 6.859,6.943]$

- $\quad(6.943,7.027]$

Figure 3. Kriging prediction for the Lead (Pb).

\section{Kriging standard error}

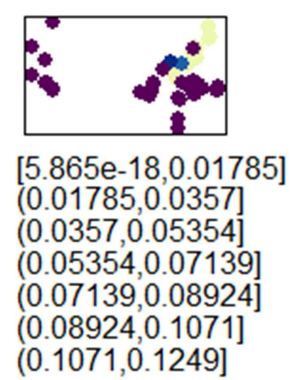

Figure 4. Kriging standard error for the Lead $(\mathrm{Pb})$.

From the result presented in Figure 3, it is indicating that the prediction variability in the concentrations of lead $(\mathrm{Pb})$ increases from north to southern part of the study area. The threshold value with the prediction variance of the concentrations of Lead $(\mathrm{Pb})$ is 0.11 to 0.12 . It was observed that from the Co-Kriging prediction map, the highest concentrations is found in Kware, Gada, Dange, Wurno and Bukuyum. And lowest value in the concentrations is found Danko Wasagu, Yauri and Zuru.

\section{Conclusion}

Based on the results obtained from the analysis, it can be concluded that the concentration of Lead $(\mathrm{Pb})$ from south to northern part of the region along Kware, Gada, Dange, Wurno and Bukuyum. It is also concluded that the concentrations of Lead $(\mathrm{Pb})$ in the region are as a result of mining, agricultural and industrial activities in the region. It can generally concluded that Co-Kriging is the efficient and essential geostatistical technique to model the environmental data.

\section{References}

[1] Fang X., Bifeng H., Shuai S., Dongyun X., Yue Z., Yin Z., Mingxiang H., Yan L., Songchao C. and Zhou S., (2019) "Improvement of spatial modelling of $\mathrm{Cr}, \mathrm{Pb}, \mathrm{Cd}, \mathrm{As}$ and $\mathrm{Ni}$ in the soil based on portable X-ray fluorescence (PXRF) and Geostatistics" Journal of environmental research and public health., 16, 2694.

[2] Gandhimathi, A., Meenambal, T., (2011). Spatial prediction of heavy metal pollution for soils in Coimbatore, India based on universal Kriging. International journal of computer applications 29 (10), 52-63.

[3] Devkota, B., Schmidt, G. H., (2000). Accumulation of heavy metals in food plants and grasshopper from the Taigetos Mountain, Greece. Agriculture, ecosystems and environment, 78 (1), 85-91.

[4] Frances S. F., Antonio M. G., Carmelo A. Z., Antonio G. S. and Pilar A. R., (2017). Spatial distribution of heavy metals and environmental quality of soil in the northern plateau of Spain by Geostatistical method. International journal of environmental research and public health. 14, 568.

[5] Adejumo, J., Obioh, I., Ogunsola, O., Akeredolu, F., Olaniyi, H., Asubiojo, O., Oluwole, A., Akanle, O., and Spyrou, N., (1994). The atmospheric deposition of major, minor and trace element within and around cement factory. Journal of Radio Analytic and Nuclear Chemistry 179, 195-204.

[6] Schuhmacher, M., Nadal, M., Domingo, J. L., (2009). Environmental monitoring of $\mathrm{PCDD} / \mathrm{Fs}$ and metals in the vicinity of cement plant after using sewage sludge as secondary fuel. Chemosphere 74, 1502-1508.

[7] CPCB (Central Pollution Control Board), (2007). Assessment of fugitive emission and development of environmental guidelines for control fugitive emission in cement manufacturing industries, programme objective series probes/118/2017, Delhi, India pp. 34-110. 
[8] Ogunkunle, C. O., Fatoba, P. O., (2014). Contamination and spatial distribution of heavy metals in topsoil surrounding a mega cement factory. Journal of atmospheric pollution research 5, 270-282.

[9] Achternbosch, M., Brautigam, K. R., Herlieb, N., Kupsch, R., Richers, U., Stemmermann, P., (2003). Heavy metals in cement and concrete resulting from Co-incineration of waste in cement kilns with regard to the legitimacy of waste utilization, Mitglied der Hermann vonn HelmholtzGemeinschaft Deutscher Forschungszentren, ISSN 0947-8620, pp. 22-23.

[10] Kataba P., A. Mukherjee, A. B., (2007). Trace element from soil to human, Springer verlag, Berlin, pp. 1-48.

[11] Krige, D. G., (1951). A statistical approach to some basic mine valuation on the Witwatersrand. Journal of the Chemical, Metallurgical and Mining Society, 52: 119-139.

[12] Matheron, G., (1963). Le Krigeage universal. Vol. 1. Cahiers du Centre de Morphologie Mathematique, Ecole des Mines de Paris, Fontainebleau, p. NA.

[13] Webster, R., Oliver, M., (2001). Geostatistics for Environmental Scientists Statistics in Practice. Wiley, Chichester, 271pp.

[14] David, M. (1977). Geostatistical Ore reserve estimation. Amsterdam: Elsevier.

[15] Burrough, P., (1993). Soil Variability: a late 20th century view. Soils and Fertilizers, 56: 529562.

[16] Burgess, T. M., and Webster, R., (1980). Optimal interpolation and isarithmic mapping of soil properties: The semi-variogram and punctual kriging. Journal Soil Science., 31: 315-331.

[17] Webster, R., (1994). The development of Pedometrics. Geoderma, 62: 1-15.

[18] McGrath, D. and Zhang, C., (2003). Spatial distribution of soil organic carbon Concentrations in Grassland of Ireland. Applied Geochemistry, 18: 16291639.

[19] Goovaerts, P., (1999). Geostatistics in soil science: state-ofthe-art and perspectives. Geoderma, 89 (1-2): 1-45.

[20] Webster, R. and Oliver, M. A., (2001). Geostatistics for Environmental Scientists. John Wiley and Sons Ltd, Chichester.

[21] Goovaerts, P., (1997). Geostatistics for Natural Resource Evaluation, Oxford Univ. Press, New York.

[22] Odeh, I. O. A., McBratney A. B. and Chittleborough, D. J.,
(1995). Further results on prediction of soil properties from terrain attributes: heterotopic cokriging and regression-kriging. Geoderma.

[23] Mohamed S. S., Ahmed A. E., Michael A., Fullen, Talaat R. E., Ali R. R., A. Abd E., Antonio J. T. Guerra, Maria C. O. Jorge, (2016). Spatial distribution of heavy metals in the nile delta of Egypt. International soil and water conservation research 4 , 293-303.

[24] Wedepohl, K. H., (1995). The composition of the continental crust. Geochimica et Cosmochimica Acta, 59, 1217-1239. http://dx.doi.org/10.1016/0016-7037(95)00038-2.

[25] Gandhimathi, A., Meenambal, T., (2012). Spatial prediction of heavy metal pollution for soils in Coimbatore, India based ANN and Kriging model. European scientific journal. June edition 8 (14), 79-91.

[26] Usman U., S. A. Yelwa, S. U. Gulumbe, and A. Danbaba., (2013). "An Assessment of the Changing Climate in Northern Nigeria Using Cokriging." American Journal of Applied Mathematics and Statistics 1, no. 5: 90-98. doi: 10.12691/ajams-1-5-3.

[27] Yelwa, S. A. and, U. Usman, (2017). Integration of Spatial Prediction in the Assessment of Vegetation Productivity in the Northern Part of Nigeria. American Journal of Climate Change, 6, 360-373. https://doi.org/10.4236/ajcc.2017.62018.

[28] Abbas H., Norges S. and Ali G. (2014) "Spatial variability of heavy metals in the soil of Ahwaz using geostatistics method" International Journal of Environmental Science and Development, 5 (3), 294-298.

[29] Asma, S. and Javel, I. (2018). "Spatial distribution and mobility assessment of carcinogenic heavy metals in the soil profile using geostatistics and random forest, Boruta algorithm" Sustainability, 10, 799.

[30] Myers, D. E. (1982). Matrix Formulation of Cokriging, Mathematical Geology, (14) 3, pp. 249-257.

[31] Isaaks, E. H. and Srivastava, R. M (1989). Applied Geostatistics, Oxford University Press, New York, 561 pp.

[32] Wackernagel, H. Multivariate Geostatistics, Springer-Verlag, Berlin. (1995). 255 pp.

[33] Wellmer, F. W (1998). Statistical Evaluations in Exploration for Mineral deposits, Springer-Verlag, Berlin. $379 \mathrm{pp}$.

[34] Kalivas D. P., Triantakonstantis D. P. and Kollias V. J. (2002). "Spatial prediction of two soil properties using topographic information". Global Nest: The Int. Journal, 4 (1) 41-49. 